Supplement of Clim. Past, 14, 1441-1462, 2018

https://doi.org/10.5194/cp-14-1441-2018-supplement

(C) Author(s) 2018. This work is distributed under

the Creative Commons Attribution 4.0 License.

(c) (i)

Supplement of

\title{
The role of regional feedbacks in glacial inception on Baffin Island: the interaction of ice flow and meteorology
}

Leah Birch et al.

Correspondence to: Leah Birch (lbirch@seas.harvard.edu)

The copyright of individual parts of the supplement might differ from the CC BY 4.0 License. 


\section{Supplementary information}
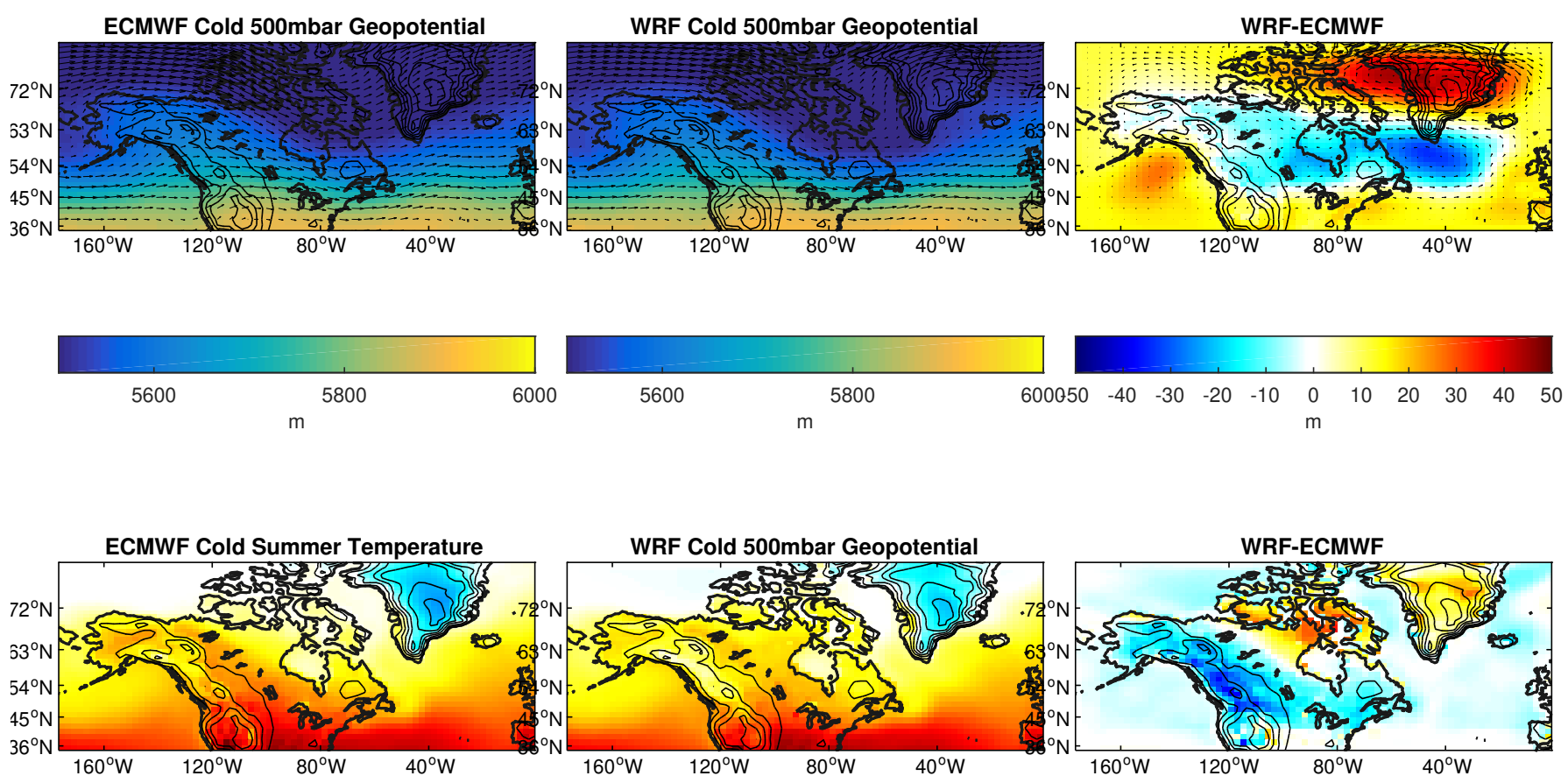

$\begin{array}{llllllllllllllllllllllllllllllllllllllllllllllllllllllllllllllllll}-30 & -25 & -20 & -15 & -10 & -5 & 0 & 5 & 10 & 15 & 20 & 25 & 30 & -30 & -25 & -20 & -15 & -10 & -5 & 0 & 5 & 10 & 15 & 20 & 25 & 30 & -10 & -9 & -8 & -7 & -6 & -5 & -4 & -3 & -2 & -1 & 0 & 1 & 2 & 3 & 4 & 5 & 6 & 7 & 8\end{array}$

Figure 1: Comparing ECMWF and WRF: Geopotential Height (JJA) for (a) ECMWF in 1986 and (b) Present Day WRF with 1986 Boundary Conditions (c) difference in JJA WRF and ECMWF. 2m Temperature (JJA) for (d) ECMWF in 1986 and (e) Present Day WRF with 1986 Boundary Conditions (f) difference in JJA WRF and ECMWF 
(a) Geo(It1)

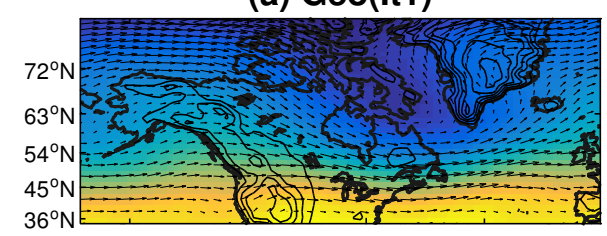

(d) Geo(It2)-Geo(It1) (b) Geo(It2)

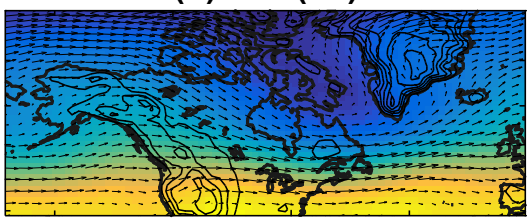

(e) Geo(No H)-Geo(It1) (c) Geo(It10)

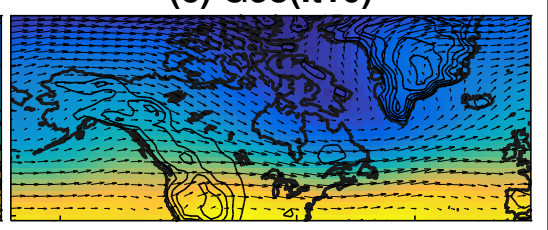

5900

5800

5700

5600

5500

5400

14

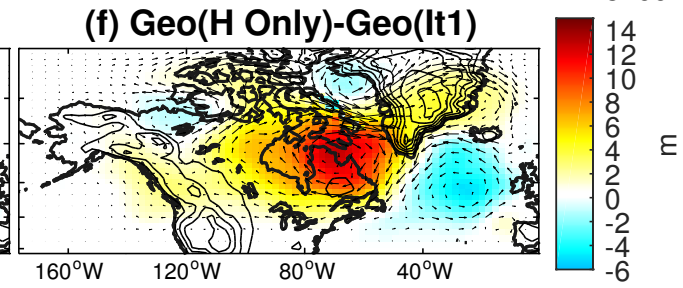

Figure 2: Geopotential height during summer (JJA) at 500 mb: (a) It 1, (b) It 2, (b) It 10, and Geopotential height differences JJA (d) It 2-It 1, (e) Ice with no elevation change (No H) minus It 1, (f) changing the topography to be equal to that of It2 without ice minus It 1 
(a) Snow Melt
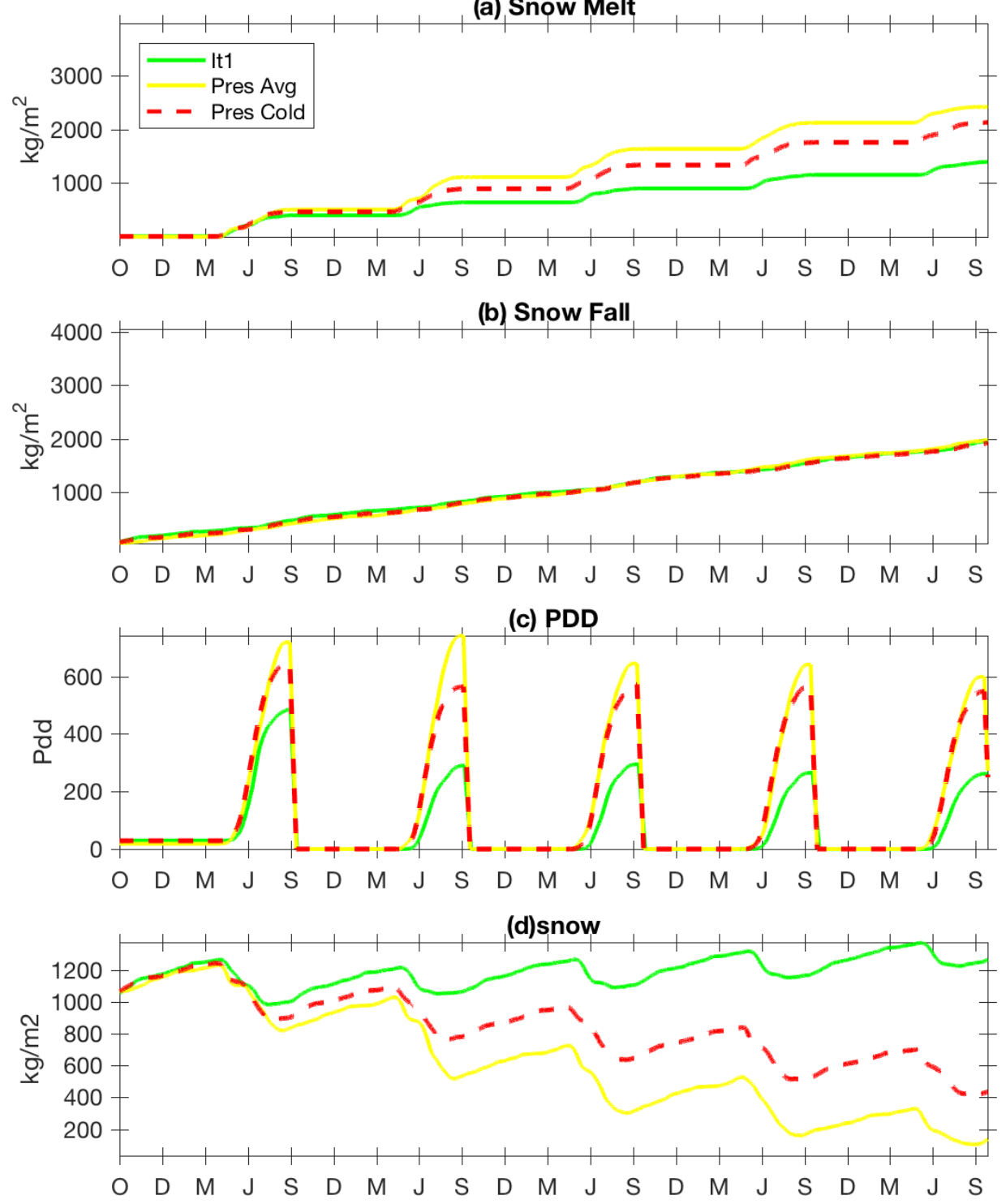

Figure 3: Time series comparison of WRF simulations: 115 kya with 1986 cold boundary conditions, present day 1986 cold meteorology, and present day 1980 average meteorology. (a) Snow Melt over 5 year simulation. (b) Snow fall. (c) Positive Degree Days (PDD), less indicates colder summers with 115 kya insolation. (d) Average snow depth on the ice caps, only increases with 115 kya insolation. 


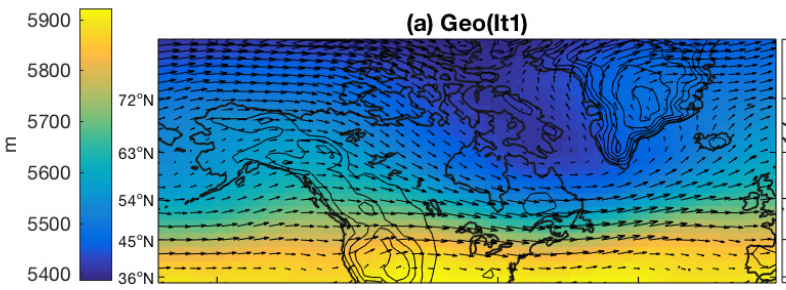

(b) Geo(It2)-Geo(It1)

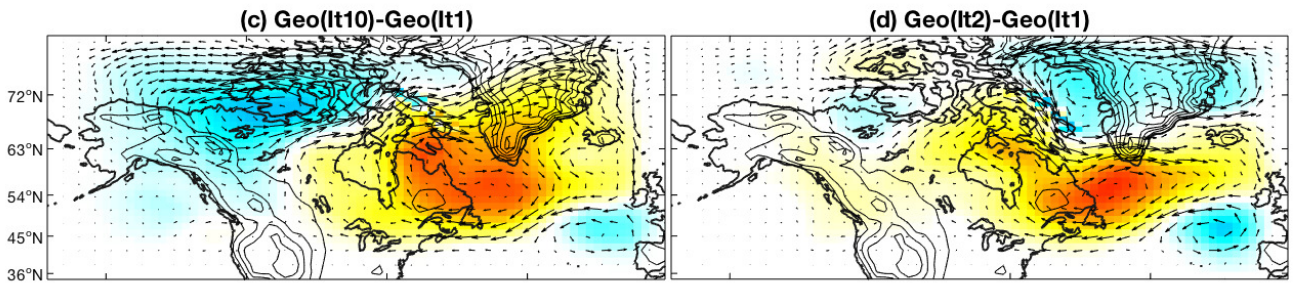

(e) Geo(It3)-Geo(It1)
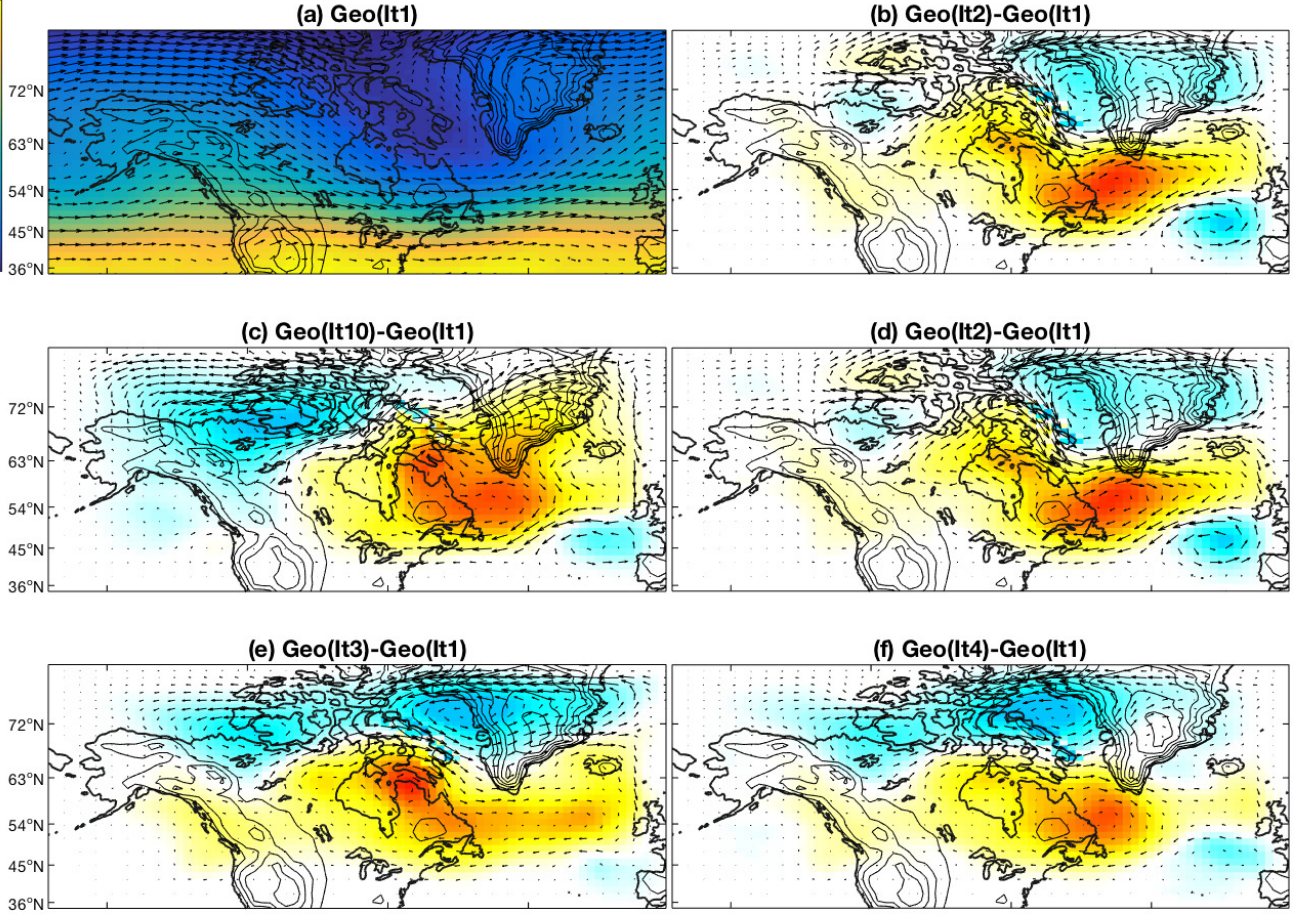

(f) Geo(It4)-Geo(It1)
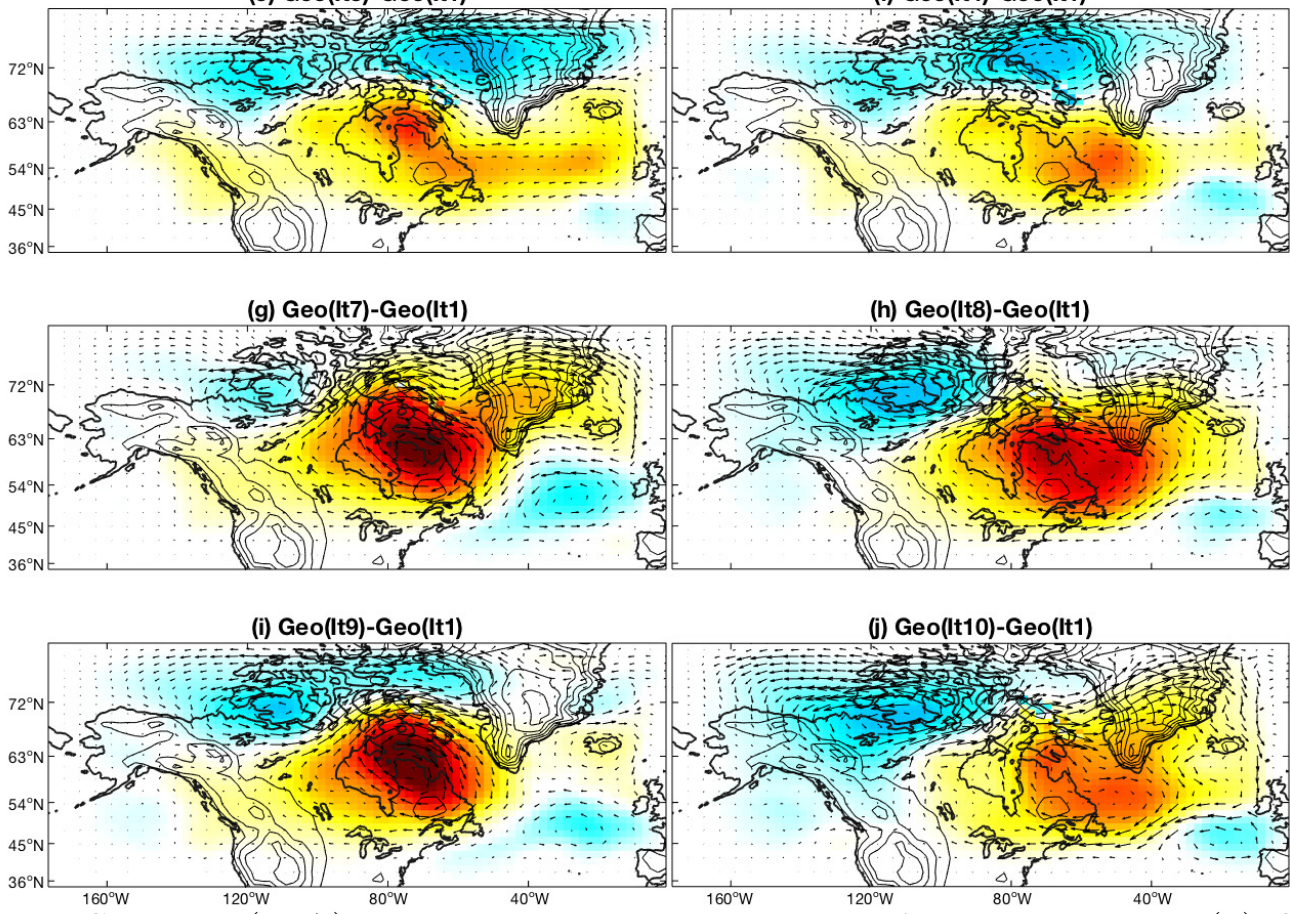

Figure 4: Summer (JJA) geopotential height anomalies for all iterations. (a) Geopotential height JJA for iteration 1. (b)-(j) Difference in iteration 1 from each subsequent iteration, indicating the progression of anti-cyclones. 

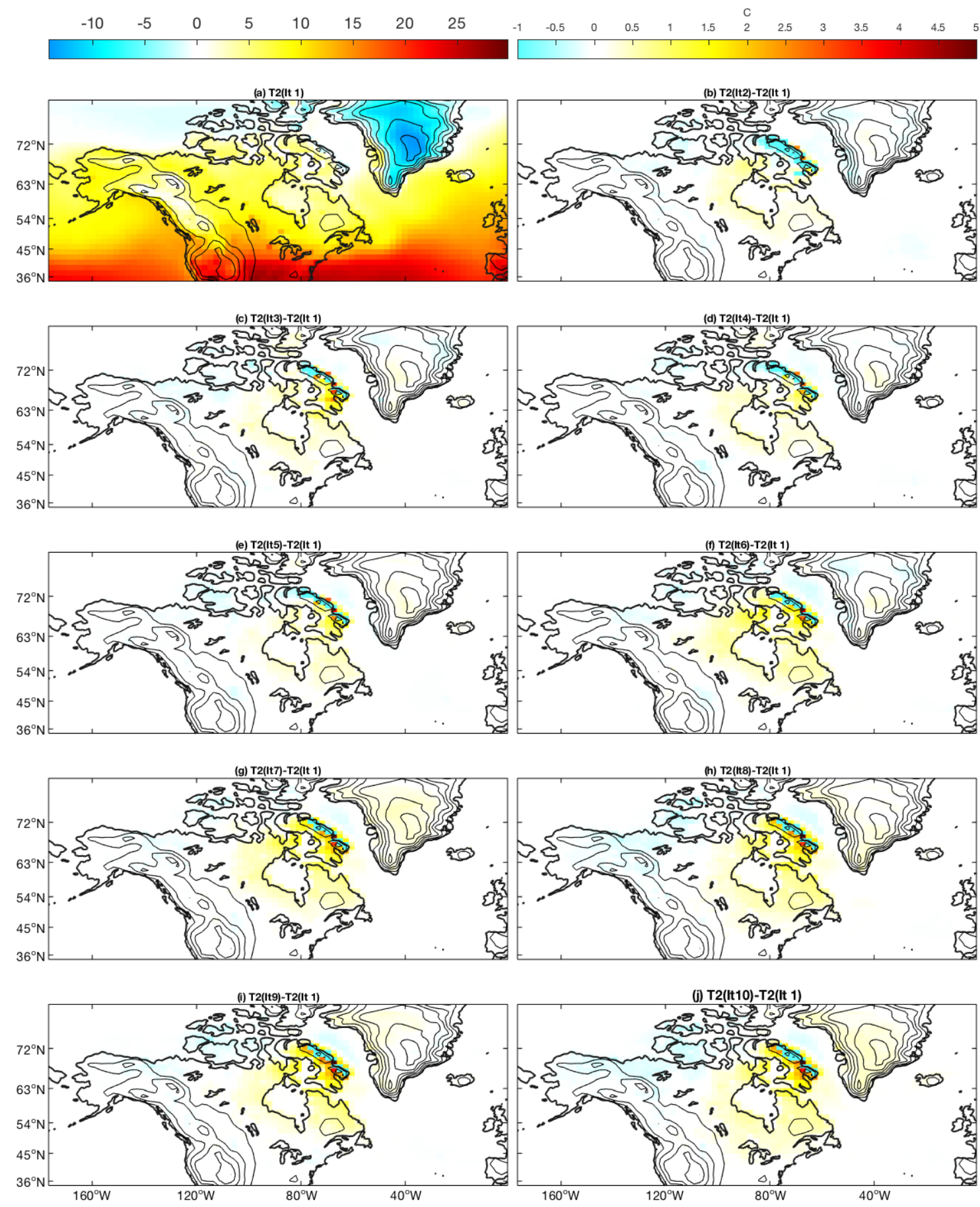

Figure 5: Summer (JJA) 2m Temperature anomalies for all iterations. (a) $2 \mathrm{~m}$ Temperature JJA for iteration 1. (b)-(j) Difference in iteration 1 from each subsequent iteration, depicting the warming caused by ice growth. 


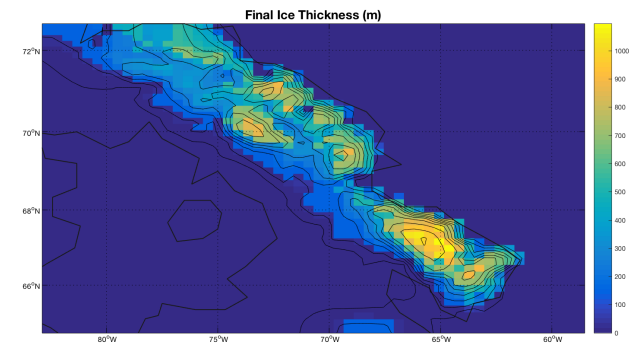

(a) Ice Model run with 20km Resolution

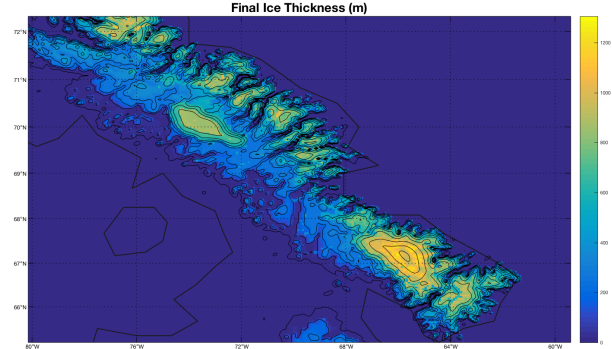

(b) Ice Model run with $4 \mathrm{~km}$ Resolution

Figure 6: Ice extent after 2nd Iteration for $20 \mathrm{~km}$ and $4 \mathrm{~m}$ Resolutions. The mass balance profile $(\mathrm{G}(\mathrm{H}))$ is derived in the same way as the methods second with the mass balance coming from the $20 \mathrm{~km}$ WRF simulation. The only difference is that $\mathrm{G}(\mathrm{H})$ is now updated using the $4 \mathrm{~km}$ resolution. 